\title{
Efeitos do treinamento concorrente e aconselhamento dietético na lipodistrofia e sua repercussão na adesão ao tratamento do HIV/aids: um relato de caso
}

\author{
Effects of concurrent training and dietary advice in lipodystrophy and their impact on \\ adherence to treatment for HIV/AIDS: a case report
}

Danielle Coutinho de Medeiros ${ }^{1}$, Carla Glenda Souza Silva², Hunaway Albuquerque Galvão de Souza ${ }^{3}$, Rafaela Catherine da Silva Cunha de Medeiros ${ }^{4}$, Jason Azevedo de Medeiros ${ }^{4}$, Tatiane Andreza Lima da Silva ${ }^{1}$, Elys Costa de Souza ${ }^{1}$, Paulo Moreira Silva Dantas ${ }^{5}$

\begin{abstract}
Mestrandas do Programa de Pós-Graduação em Ciências da Saúde, Centro de Ciências da Saúde, Universidade Federal do Rio Grande do Norte (UFRN), Bolsistas da CAPES ${ }^{2}$ Mestre em Ciências da Saúde pela UFRN, Doutoranda do Programa de Pós-Graduação em Ciências da Saúde pela UFRN; ${ }^{3}$ Mestre em Ciências da Saúde pela UFRN, Doutoranda do Programa de Pós-Graduação em Educação da UFRN, Professora da Universidade Estadual do Rio Grande do Norte (UERN); ${ }^{4}$ Mestrandos do Programa de Pós-Graduação de Educação Física da UFRN; ${ }^{5}$ Doutor em Ciências da Saúde, Mestre em Ciências da Motricidade Humana, Professor Adjunto da UFRN no Departamento de Educação Física, Professor do Programa de Pós-Graduação em Ciências da Saúde da UFRN, Professor do Programa de Pós-Graduação em Educação Física da UFRN, Professor convidado da Universidade de Trás-os-Montes e Alto Douro, Portugal.
\end{abstract}

Este estudo teve apoio financeiro através de bolsas da Coordenação de Aperfeiçoamento de Pessoal de Nível Superior (CAPES).

\section{RESUMO}

Objetivos: Descrever as mudanças corporais relacionadas à lipodistrofia de um homem com HIV/aids, após um programa de treinamento concorrente e aconselhamento dietético, e suas repercussões na adesão ao tratamento.

Descrição do Caso: Indivíduo de sexo masculino, 48 anos, sedentário, diagnosticado 13 anos antes como HIV positivo. Foi realizada uma intervenção com o treinamento concorrente e aconselhamento dietético e avaliou-se a composição corporal e a resposta virológica e imunológica ao exercício, que apresentou resultados satisfatórios.

Conclusões: O treinamento concorrente mostrou-se um método efetivo como terapia coadjuvante para o paciente em vigência de terapia antirretroviral de alta atividade, melhorando a lipodistrofia e a adesão ao tratamento.

DESCRITORES: TERAPIA ANTIRRETROVIRAL DE ALTA ATIVIDADE; DIETA; EXERCÍCIO; COMPOSIÇÃO CORPORAL; HIV.

\section{ABSTRACT}

Aims: To describe the body changes associated with lipodystrophy of a man with HIV/AIDS, after a program of concurrent training and dietary advice, and their impact on treatment adherence.

Case Description: A male patient, 48 years old, sedentary, was diagnosed 13 years before as HIV positive. An intervention was performed with concurrent training and dietary advice. The body composition and virological and immunological response to exercise were evaluated, and had satisfactory results.

Conclusions: Concurrent training proved to be an effective method as adjuvant therapy for patients in the highly active antiretroviral therapy, improving the lipodystrophy and the adherence to treatment.

KEY WORDS: ANTIRETROVIRAL THERAPY, HIGHLY ACTIVE; DIET; EXERCISE; BODY COMPOSITION; HIV.

Recebido em novembro de 2013; aceito em abril de 2014. 


\section{INTRODUÇÃO}

A lipodistrofia representa um dos efeitos adversos da terapia antirretroviral de alta atividade (HAART), podendo resultar na má adesão ao tratamento. Para o controle da lipodistrofia, são recomendadas intervenções não medicamentosas, ${ }^{1,2}$ sendo o exercício físico e a boa alimentação capazes de melhorar a adesão e a efetividade da HAART. ${ }^{3,4}$

Diante do exposto, o estudo objetiva descrever as mudanças corporais relacionadas à lipodistrofia de um homem com HIV/aids, após um programa de treinamento concorrente e aconselhamento dietético, e suas repercussões na adesão ao tratamento.

Este estudo foi aprovado pelo Comitê de Ética em Pesquisa da Universidade Federal do Rio Grande do Norte (UFRN) sob protocolo 230/11.

\section{RELATO DO CASO}

O estudo relata o caso de um indivíduo de sexo masculino, 48 anos, sedentário, soropositivo para HIV, com diagnóstico confirmado há 13 anos. Há aproximadamente seis anos, o esquema terapêutico da HAART utilizado por ele era composto por Biovir ${ }^{\circledR}$, Nevirapina $^{\circledR}$ e Atazanavir ${ }^{\circledR}$.

$\mathrm{O}$ indivíduo ingressou no projeto de extensão e pesquisa "Viver +" (PVHA), da UFRN, o qual oferece programa de exercício físico e aconselhamento dietético personalizado, destinado às pessoas com HIV e aids. A pré-avaliação laboratorial revelou estado imunológico e virológico estável, porém a avaliação física detectou sinais evidentes de lipodistrofia mista: lipo-hipertrofia central e lipoatrofia de membros e quadril.

Com base nas necessidades obtidas pelas avaliações, realizou-se a intervenção com um protocolo de treinamento concorrente, caracterizado por exercícios aeróbicos e resistido numa mesma sessão de treino, conforme Lazzarotto et al., ${ }^{5}$ e um aconselhamento dietético. Toda a intervenção teve um período de 16 semanas de duração, sendo o aconselhamento dietético incluído a partir da oitava semana, devido à resistência inicial do paciente, $o$ qual se motivou a incorporar o plano alimentar somente após observar mudanças em seu corpo.

O treinamento consistiu em 25 minutos de caminhada moderada $-60 \%$ e $80 \%$ da frequência cardíaca máxima (FCMax) $-{ }^{6}$ monitorada pelo frequencímetro Polar F1 ${ }^{\circledR}$; e treinamento resistido, priorizando as regiões mais afetadas pela lipodistrofia (nível 8 na escala de Omnires), ${ }^{7}$ com intervalo de descanso entre 60 e 90 segundos, três vezes por semana.
O programa de exercícios resistidos foi dividido em treino A e B. Treino A, direcionado aos músculos quadríceps, peitoral, panturrilha, bíceps, ombro e reto abdominal; e treino B, aos isquiotibiais, dorsais, glúteos, tríceps e abdômen (porção lateral e oblíqua).

Os exercícios prescritos foram baseados no Guia de Movimentos de Musculação de Delavier, 2006. ${ }^{8}$ Dessa forma o treino A consistiu em leg press inclinado (pés posicionados baixos sobre a plataforma), abduçãoadução com aparelho específico, extensão de joelhos com aparelho específico, supino (bench press), extensão dos pés (prensa dos sóleos), flexão dos antebraços com barra (mãos em supinação), desenvolvimento sentado com halteres e abdominais no solo. O treino B consistiu em leg press inclinado (pés posicionados altos sobre a plataforma), puxada na frente com polia alta, flexora de joelhos com aparelho específico, puxada com polia baixa (mãos juntas e em semipronação), elevação da pelve do solo, tríceps com polia alta (mãos em pronação), flexão lateral do tronco com halteres e rotação do tronco.

O método utilizado para a execução do treino consistiu na realização de dois exercícios consecutivos (um para membros inferiores e outro para membros superiores). Para exercícios resistidos foram adotadas três séries de 12 repetições e, para os abdominais, três séries de 20 repetições. O aconselhamento dietético foi baseado na orientação para redução de gorduras saturadas e carboidratos simples, e aumento de fibras.

Realizaram-se avaliações físicas para verificar a composição corporal do paciente na fase intermediária ( $8^{a}$ semana) e na fase final do protocolo de treinamento (16 ${ }^{\mathrm{a}}$ semana), incluindo a mensuração $(\mathrm{em} \mathrm{cm}) \mathrm{de}$ perimetrias de tórax, cintura, braço e coxa medial, e mensuração (em mm) de dobras cutâneas de subescapular, suprailíaca, supraespinhal, coxa média, biciptal e triciptal, conforme os padrões da International Society for the Advancement of Kinanthropometry (ISAK) $;{ }^{9}$ e dobra cutânea de tórax, segundo Lohman et al. ${ }^{10}$ Para tanto, utilizou-se fita antropométrica inelástica Sanny ${ }^{\circledR}$ e adipômetro Harpenden ${ }^{\circledR}$.

A partir de tais mensurações, realizou-se também o somatório das dobras cutâneas por regiões: tronco inferior (supraespinhal e suprailíaca), tronco superior (subescapular e tórax), membros inferiores (coxa medial) e membros superiores (bíceps e tríceps); calculou-se o percentual de mudança corporal, o índice médio de mudança e os diâmetros corrigidos por região.

Os resultados dessas avaliações físicas revelaram o declínio da gordura central das regiões tronco inferior e tronco superior, e melhoria da composição corporal do indivíduo, evidenciada pela redução da perimetria de cintura, das dobras cutâneas e aumento de massa 
muscular do tórax. Os membros inferiores e superiores também apresentaram reduções em seus somatórios de dobras cutâneas após a intervenção, acompanhados de redução nas perimetrias de coxa média e braço, porém o diâmetro corrigido demonstrou a manutenção da massa muscular (Tabela 1).

Os parâmetros imunológicos e virológicos, mensurados através dos exames laboratoriais de contagem de linfócitos T CD4+ e carga viral também foram reavaliados após o término do protocolo de treinamento. A contagem de Linfócitos T CD4+ foi analisada através da técnica de Citometria de Fluxo (Facscalibur, Multitest); e a carga viral, pelo método Abbott al Time HIV1. Em relação a tais variáveis, observou-se o aumento dos linfócitos T CD4+ e a manutenção da carga viral em parâmetros indetectáveis $\left(<50\right.$ cópias $\left./ \mathrm{mm}^{3}\right)$ (Tabela 2$)$.

\section{DISCUSSÃO}

Os resultados deste estudo sugerem que o programa de treinamento concorrente associado ao aconselhamento dietético favoreceu a redução da lipo-hipertrofia, ${ }^{11-14}$ a remodelação corporal afetada pela HAART e a minimização dos riscos relacionados à síndrome lipodistrófica, os quais estão relacionados a distúrbios no metabolismo da glicose, dislipidemias e eventos cardiovasculares.

Apesar de alguns estudos afirmarem que a atividade física pode acentuar a lipoatrofia, ${ }^{15-16}$ este caso demonstrou o controle desse efeito em toda a região periférica. Corroborando com este achado, Driscoll et al, ${ }^{17}$ Yarasheski et al. ${ }^{18}$ e Mendes et al. ${ }^{19}$ também observaram aumento de massa muscular nessas regiões.

Tabela 1. Variáveis da composição corporal e percentuais de mudança corporal a cada avaliação, em um paciente com HIV/ aids, durante um programa de treinamento concorrente e aconselhamento dietético.

\begin{tabular}{|c|c|c|c|c|}
\hline$\Sigma$ dobras cutâneas & Suprailíaca + supraespinhal & Subescapular + tórax & Coxa média & Tríceps + bíceps \\
\hline 1a semana & 51,2 & 44,3 & 15,5 & 16,3 \\
\hline $8^{\underline{a}}$ semana & 49 & 36 & 12,5 & 16,3 \\
\hline $16^{\mathrm{a}}$ semana & 46,4 & 40,1 & 13,5 & 14,9 \\
\hline Perimetria & Cintura & Tórax & Coxa média & Braço relaxado \\
\hline 1a semana & 85,5 & 91 & 51,5 & 29 \\
\hline $8^{\underline{a}}$ semana & 85 & 95,5 & 49 & 28,8 \\
\hline $16^{\mathrm{a}}$ semana & 8 & 95,5 & 49 & 27,5 \\
\hline Diâmetro corrigido & Cintura & Tórax & Coxa média & Braço relaxado \\
\hline 1’a semana & 25,6 & 27,6 & 15,9 & 8,7 \\
\hline $8^{\underline{a}}$ semana & 25,5 & 29,3 & 15,2 & 8,6 \\
\hline $16^{\mathrm{a}}$ semana & 25,6 & 29,1 & 15,2 & 8,3 \\
\hline$\% \mathrm{MC}$ & Suprailíaca + supraespinhal & Subescapular + tórax & Coxa média & Tríceps + Bíceps \\
\hline 1a semana & $0 \%$ & $0 \%$ & $0 \%$ & $0 \%$ \\
\hline $8^{\underline{a}}$ semana & $-4,30 \%$ & $-18,70 \%$ & $-9,40 \%$ & $0 \%$ \\
\hline $16^{\mathrm{a}}$ semana & $-9,40 \%$ & $-9,5$ & $-12,90 \%$ & $-8,60 \%$ \\
\hline$\%$ IMM & $-6,80 \%$ & $-14,10 \%$ & $-6,10 \%$ & $-4,30 \%$ \\
\hline
\end{tabular}

$\sum$ : Somatório.

Diâmetro corrigido $=\left[\right.$ Perimetria da região em $\mathrm{cm}-\left(\sum\right.$ de dobras cutâneas da região correspondente em $\left.\left.\mathrm{cm}\right)\right]-1 /$.

$\% \mathrm{MC}$ : porcentagem de mudança corporal.

$\%$ MC da $8^{\underline{a}}$ semana $=\left[\sum\right.$ de dobras cutâneas da região na $8^{\underline{a}}$ semana $/ \sum$ de dobra cutâneas da mesma região na $1 \underline{\underline{a}}$ semana $]-1 *(100)$.

$\%$ MC da $16^{\underline{a}}$ semana $=\left[\sum\right.$ de dobras cutâneas da região na $16^{\underline{a}}$ semana $/ \sum$ de dobras cutâneas da mesma região na $1 \underline{\underline{a}}$ semana $]-1 *(100)$

$\%$ IMM: porcentagem do índice médio de mudança $=\left[\%\right.$ MC $16^{\underline{a}}$ semana $+\%$ MC $8^{\underline{a}}$ semana $] / 2$.

Tabela 2. Parâmetros imunológico e virológico de um paciente com HIV/aids, no início (1a semana) e final (16 ${ }^{\underline{a}}$ semana) da intervenção com o protocolo de treinamento concorrente e aconselhamento dietético.

\begin{tabular}{|c|c|c|}
\hline Variáveis & $\begin{array}{l}\text { Início do Protocolo de Treinamento } \\
\text { (1] semana) }\end{array}$ & $\begin{array}{l}\text { Final do Protocolo de Treinamento } \\
\text { (16 semana) }\end{array}$ \\
\hline Contagem de células T CD4+ (células $/ \mathrm{mm}^{3}$ ) & 792 & 820 \\
\hline Carga Viral & indetectável & indetectável \\
\hline
\end{tabular}


Quanto aos parâmetros imunológicos e virológicos, o treinamento concorrente também se mostrou eficaz, mantendo o controle do estado da doença e garantindo ao paciente, além da segurança da aplicabilidade do método, uma boa adesão à terapia medicamentosa. Em consonância com estes resultados, alguns estudos também observaram aumento da contagem de linfócitos TCD4 $+{ }^{20}$ e redução na carga viral ${ }^{21}$, enquanto em outros, o TCD4+ e carga viral mantiveram-se constantes. ${ }^{11,12,17,22,23}$

Em conclusão, o treinamento concorrente associado ao aconselhamento dietético mostrou-se efetivo como terapia coadjuvante para este paciente em HAART, atuando no controle da lipodistrofia e refletindo satisfatoriamente na adesão ao tratamento.

\section{REFERÊNCIAS}

1. Segatto AFM, Freitas Junior IF, Santos VR, Alves KCP, Barbosa DA, Portelinha Filho AM, Monteiro HL. Lipodystrophy in HIV/AIDS patients with different levels of physical activity while on antiretroviral therapy. Rev Soc Bras Med Trop. 2011 Jul-Aug;44(4):420-4.

2. Trevisol F, Alencastro P, Ribeiro P, Wollf F, Ikeda M, Barcellos N, Brandão A, Fuchs S. Association of physical activity with lipodystrophy syndrome in HIV-Infected patients. J AIDS Clinic Res. 2012;3(177):2.

3. Botros D1, Somarriba G, Neri D, Miller TL. Interventions to address chronic disease and HIV: strategies to promote exercise and nutrition among HIV-infected individuals. Curr HIV/AIDS Rep. 2012 Dec;9(4):351-63.

4. World Health Organization. Adherence to long-term therapies: evidence for action. Geneva: WHO; 2003.

5. Lazzarotto AR, Deresz LF, Sprinz E. HIV/AIDS e treinamento concorrente: a revisão sistemática. Rev Bras Med Esporte. 2010;16:149-54.

6. Garber CE, Blissmer B, Deschenes MR, Franklin BA, Lamonte MJ, Lee IM, Nieman DC, Swain DP; American College of Sports Medicine. American College of Sports Medicine position stand. Quantity and quality of exercise for developing and maintaining cardiorespiratory, musculoskeletal, and neuromotor fitness in apparently healthy adults: guidance for prescribing exercise. Med Sci Sports Exerc. 2011 Jul;43(7):1334-59.

7. Robertson RJ1, Goss FL, Rutkowski J, Lenz B, Dixon C, Timmer J, Frazee K, Dube J, Andreacci J. Concurrent validation of the OMNI perceived exertion scale for resistance exercise. Med Sci Sports Exerc. 2003 Feb;35(2):333-41.

8. Delavier F. Guia de movimentos de musculação: uma abordagem anatômica. $5^{\mathrm{a}}$ ed. São Paulo: Manole; 2006.

9. Marfell-Jones, M; Olds, T; Stewart, A; Carter, L. International standards for anthropometric assessment. Lower Hutt: ISAK; 2006.

10. Lohman TG, Roche AF, Martorell R, editors. Anthropometric standardization reference manual. Champaign, IL: Human Kinetics; 1988.

11. Dolan SE1, Frontera W, Librizzi J, Ljungquist K, Juan S, Dorman R, Cole ME, Kanter JR, Grinspoon S. Effects of a supervised homebased aerobic and progressive resistance training regimen in women infected with human immunodeficiency virus: a randomized trial. Arch Intern Med. 2006 Jun 12;166(11):1225-31.

12. Engelson ES, Agin D, Kenya S, Werber-Zion G, Luty B, Albu JB, Kotler DP. Body composition and metabolic effects of a diet and exercise weight loss regimen on obese, HIV-infected women. Metabolism. 2006 Oct;55(10):1327-36.

13. Robinson FP, Quinn LT, Rimmer JH. Effects of high-intensity endurance and resistance exercise on HIV metabolic abnormalities: a pilot study. Biol Res Nurs. 2007 Jan;8(3):177-85.

14. Roubenoff R, Weiss L, McDermott A, Heflin T, Cloutier GJ, Wood M, Gorbach S. A pilot study of exercise training to reduce trunk fat in adults with HIV-associated fat redistribution. AIDS. 1999 Jul 30;13(11):1373-5.

15. Florindo AA1, de Oliveira Latorre Mdo R, Jaime PC, Segurado AA. Leisure time physical activity prevents accumulation of central fat in HIV/AIDS subjects on highly active antiretroviral therapy. Int J STD AIDS. 2007 Oct;18(10):692-6.

16. Smith BA, Neidig JL, Nickel JT, Mitchell GL, Para MF, Fass RJ. Aerobic exercise: effects on parameters related to fatigue, dyspnea, weight and body composition in HIV-infected adults. AIDS. 2001 Apr 13;15(6):693-701.

17. Driscoll SD1, Meininger GE, Lareau MT, Dolan SE, Killilea KM, Hadigan CM, Lloyd-Jones DM, Klibanski A, Frontera WR, Grinspoon SK. Effects of exercise training and metformin on body composition and cardiovascular indices in HIV-infected patients. AIDS. 2004 Feb 20;18(3):465-73.

18. Yarasheski KE, Tebas P, Stanerson B, Claxton S, Marin D, Bae K, Kennedy M, Tantisiriwat W, Powderly WG. Resistance exercise training reduces hypertriglyceridemia in HIV-infected men treated with antiviral therapy. J Appl Physiol. 2001 Jan;90(1):133-8.

19. Mendes EL, Andaki ACR, Amorim PRdS, Natali AJ, Brito CJ, Paula SO. Physical training for HIV positive individuals submitted to HAART: effects on anthropometric and functional parameters. Rev Bras Med Esporte. 2013;19(1):16-21.

20. Lazzarotto AR. O treinamento concorrente com séries simples nos parâmetros imunológico, virológico, cardiorrespiratório e muscular de indivíduos infectados pelo vírus da imunodeficiência humana tipo 1. Porto Alegre: UFRGS; 2007.

21. Grinspoon S, Corcoran C, Parlman K, Costello M, Rosenthal D, Anderson E, Stanley T, Schoenfeld D, Burrows B, Hayden D, Basgoz N, Klibanski A. Effects of testosterone and progressive resistance training in eugonadal men with AIDS wasting a randomized, controlled trial. Ann Intern Med. 2000 Sep 5;133(5):348-55.

22. Fillipas S1, Oldmeadow LB, Bailey MJ, Cherry CL. A six-month, supervised, aerobic and resistance exercise program improves selfefficacy in people with human immunodeficiency virus: a randomised controlled trial. Aust J Physiother. 2006;52(3):185-90.

23. Rojas R, Schlicht W, Hautzinger M. Effects of exercise training on quality of life, psychological well-being, immune status, and cardiopulmonary fitness in an HIV-1 positive population. J Sport Exerc Psychol. 2003;25(4):440-55. C 